\title{
Rancang Ulang Saluran Drainase Kampung Lalang dengan Metode Drainase Biopori Resapan
}

\section{Redesign Kampung Lalang Drainage Channel with Biopore Infiltration of Drainage Method}

\author{
Fikri Auza'I Ikhwan'), Rizky Franchitika') \\ Jurusan Teknik Sipil, Fakultas Teknik Sipil dan Perencanaan \\ Institut Teknologi Medan, Indonesia \\ *Corresponding, Email: kruzierauchter@gmail.com
}

\begin{abstract}
Abstrak
Drainase merupakan salah satu sarana prasarana kehidupan masyarakat di perkotaan, namun sayangnya banyak drainase yang tidak berfungsi sebagaimana semestinya sehingga terkesan drainase tiada berguna. Salah satu fungsi drainase ialah sebagai bangunan pencegah banjir dan pengendalian air dalam suatu wilayah, namun nyatanya banjir masih saja terjadi salah satunya pada daerah kampung lalang, dimana salah satu penyebabnya ialahnya tidak sesuainya antara debit banjir dengan besarnya dimensi saluran. Drainase biopori resapan merupakan salah satu solusi guna mengatasi masalah ini dimana air limpahan sebagian akan dikembalikan menjadi air tanah.
\end{abstract}

Kata kunci: Drainase, Biopori Resapan, Banjir

\begin{abstract}
Drainage is one of the infrastructure facilities for people's lives in urban areas, but unfortunately there are many drainages that do not function properly so that drainage seems useless. One of the functions of drainage is as a building to prevent flooding and control water in an area, but in fact floods still occur, one of which is in the Kampung Lalang area, where one of the causes is the mismatch between the flood discharge and the size of the channel dimensions. Biopore infiltration drainage is one solution to overcome this problem where some of the overflow water will be returned to groundwater.
\end{abstract}

Keywords: Drainage, Biopore Infiltration, Flood

How to Cite: Ikhwan, F. A., Franchitika, R. (2021). Rancang Ulang Saluran Drainase Kampung Lalang dengan Metode Drainase Biopori Resapan. JCEBT (Journal of Civil Engineering, Building and Transportation). 5 (2): 126 - 131 


\section{PENDAHULUAN}

Drainase merupakan salah satu sarana dan prasarana kehidupan di perkotaan. Dimana drainase berfungsi sebagai menyalur air dari suatu kawasan ke kawasan lainnya sehingga fungsi dari kawasan tersebut dalam dijalankan dengan baik. Selain itu drainase juga berfungsi sebagai bangunan pengendali banjir pada suatu kawasan. Pembangunan drainase tentunya melalui tahapan perencanaan dimana luasan dimensi saluran akan disesuaikan dengan besarnya debit banjir yang akan terjadi dikawasan tersebut. Namun, sayangnya seiring dengan perkembangan masa debit banjir kedepannya pasti akan terus bertambah sedangkan luasan dimensi saluran atau ukuran saluran tidak mengalami perkembangan sehingga akhinrya drainase yang telah ada tak mampu menampung debit banjir yang ada secara keseluruhan dan terjadilah banjir.

Drainase Biopori Resapan merupakan salah satu inovasi yang dapat dijadikan jawaban atas permasalahan ini dimana air banjir yang ada tidaklah seluruhnya dilairkan oleh sistem drainase menuju saluran utama atau sungai melainkan sebagian akan dialirkan kembali kedalam tanah dan menjadi air tanah, sehingga demikian air limpasan yang tak tertampung pada saluran akan di limpahkan menuju lubang-lubang biopori resapan yang dirancang.

Adapun permasalah yang menjadi dasar penulisan adalah:

Bentuk saluran drainase yang akan digunakan.

Jumlah debit banjir rencana hingga kala ulang 100 tahun.

Drainse yang merupakan salah satu bangunan pencegah banjir merupakan konstruksi yang seharusnya dapat berfungsi dengan baik sehingga perkotaan tidak mengalami kebanjiran, dengan adanya sistem ini, maka diharapkan tidak akan terjadi banjir yang disebabkan tidak sesuainya besaran debit banjir dengan besaran dimensi saluran.

\section{METODE PENELITIAN}

Menurut Peraturan Menteri Pekerjaan Umum Republik Indonesia Nomor 12 / PRT / M / 2014 dalam pasal 1 ayat 3 menerangkan bahwa sistem drainase perkotaan adalah satu kesatuan sistem teknis dan non-teknis dari prasarana dan sarana drainase. Dimana prasarana drainase adalah saluran saluran alami yang terbentuk secara alamiah dan mengalirkan air dari suatu area menuju area lainnya, 
sedangkan sarana drainase diartikan sebagai bangunan bantuan yang sengaja dibangun guna mengalirkan air dan mengendalikan air.

Drainase yang notabenenya merupakan salah satu infrastruktur perkotaan tentunya memiliki fungsi-fungsi tersendiri, diantaranya adalah sebagai berikut:

Saluran yang mengalirkan air dari suatu kawasan menuju kawasan lainnya.

Mencegah terjadinya banjir di suatu daerah.

Pengontrol jumlah air dalam suatu kawasan.

Lubang biopori resapan merupakan suatu konstruksi yang berawal dari lubang biopori, namun ada perbedaan diantara keduanya. Pada lubang biopori lubang yang terbentuk alami dikarenakan biota tanah namun pada lubang biopori resapan lubang yang ada memang sengaja dibentuk untuk tujuan tertentu, diantaranya ialah mengembalikan air hujan kedalam tanah.

Diantara manfaat lubang biopori resapan ialah:

1. Mencegah banjir.

2. Meningkatkan daya resapan air.

3. Menjaga keadaan alam sekitar.

Drainase biopori resapan merupakan inovasi baru yang menggabungkan antara sistem drainase konvensional dengan metode biopori resapan. Cara kerja sistem drainase konvensional yaitu membuang air yang melaju pada salurannya ke saluran utama ataupun sungai. Sedangkan dalam penerapan metode biopori resapan air yang ada padanya akan dikembalikan atau dialirkan kedalam tanah. tentunya keduanya memiliki perbedaan dan keuntungan masing-masing, namun bila keduanya digabungkan dalam satu konstruksi baru kita bisa mendapatkan suatu keuntungan.

Dalam penulisan ini, dikembangkan metode drainase biopori resapan untuk menanggulangi banjir yang terjadi di daerah perkotaan dengan mengambil konsep keduanya dan digabungkan diharapkan hasil akhirnya mampu menjadi jawaban atas permasalahan antara tidak sesuainya debit banjir dan dimensi saluran.

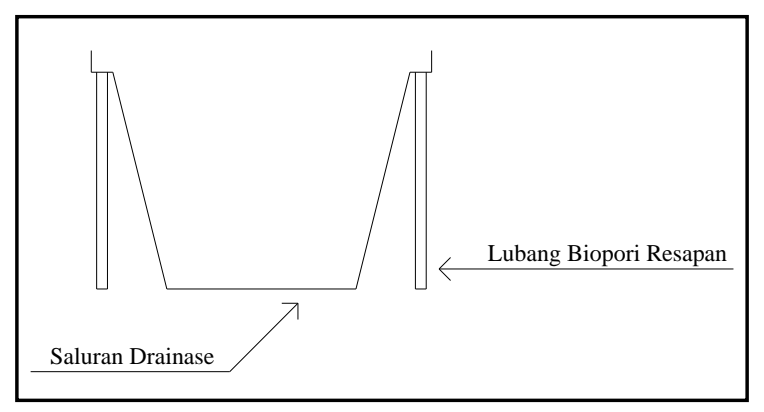

Gambar 1. Dimensi Saluran Drainase Biopori Resapan 


\section{HASIL DAN PEMBAHASAN}

Intensitas hujan adalah tinggi atau kedalaman air hujan persatuan waktu. Dimana rumusan paling umum yang digunakan dalam analisa hidrologi adalah intensitas curah hujan dengan metode Dr. Mononobe. Dimana R24 adalah nilai curah hujan rencana yang dapat dilihat pada Tabel 1. dan $\mathrm{t}$ adalah waktu sepanjang 24 jam.

Tabel 1. Intensitas Curah Hujan

\begin{tabular}{|c|c|c|c|c|c|c|c|}
\hline $\begin{array}{c}\mathrm{T} \\
(\mathrm{Jam})\end{array}$ & $\begin{array}{c}\mathrm{R}_{24} \\
\mathrm{R}_{2}\end{array}$ & $\mathrm{R}_{5}$ & $\mathrm{R}_{10}$ & $\mathrm{R}_{25}$ & $\mathrm{R}_{50}$ & $\mathrm{R}_{75}$ & $\mathrm{R}_{100}$ \\
\hline & 237.710 & 539.610 & 587.166 & 749.500 & 893.533 & 958.292 & 1023.051 \\
\hline 1 & 82.409 & 187.072 & 203.559 & 259.837 & 309.771 & 332.221 & 354.672 \\
\hline 2 & 51.915 & 117.848 & 128.234 & 163.687 & 195.143 & 209.286 & 223.429 \\
\hline 3 & 39.618 & 89.935 & 97.861 & 124.917 & 148.922 & 159.715 & 170.509 \\
\hline 4 & 32.704 & 74.240 & 80.783 & 103.116 & 122.933 & 131.842 & 140.752 \\
\hline 5 & 28.184 & 63.978 & 69.616 & 88.863 & 105.940 & 113.618 & 121.296 \\
\hline 6 & 24.958 & 56.655 & 61.649 & 78.693 & 93.815 & 100.614 & 107.414 \\
\hline 7 & 22.521 & 51.122 & 55.628 & 71.007 & 84.653 & 90.788 & 96.923 \\
\hline 8 & 20.602 & 46.768 & 50.890 & 64.959 & 77.443 & 83.055 & 88.668 \\
\hline 9 & 19.046 & 43.236 & 47.047 & 60.054 & 71.594 & 76.783 & 81.972 \\
\hline 10 & 17.755 & 40.303 & 43.856 & 55.980 & 66.738 & 71.575 & 76.412 \\
\hline 11 & 16.662 & 37.822 & 41.156 & 52.534 & 62.629 & 67.169 & 71.708 \\
\hline 12 & 15.723 & 35.691 & 38.836 & 49.573 & 59.100 & 63.383 & 67.666 \\
\hline 13 & 14.906 & 33.836 & 36.818 & 46.997 & 56.029 & 60.090 & 64.150 \\
\hline 14 & 14.187 & 32.205 & 35.043 & 44.732 & 53.328 & 57.193 & 61.058 \\
\hline 15 & 13.549 & 30.757 & 33.468 & 42.721 & 50.931 & 54.622 & 58.313 \\
\hline 16 & 12.979 & 29.462 & 32.059 & 40.922 & 48.786 & 52.322 & 55.857 \\
\hline 17 & 12.465 & 28.295 & 30.789 & 39.301 & 46.853 & 50.249 & 53.645 \\
\hline 18 & 11.999 & 27.237 & 29.638 & 37.831 & 45.102 & 48.370 & 51.639 \\
\hline 19 & 11.574 & 26.273 & 28.588 & 36.492 & 43.505 & 46.658 & 49.811 \\
\hline 20 & 11.185 & 25.390 & 27.627 & 35.265 & 42.042 & 45.089 & 48.136 \\
\hline 21 & 10.827 & 24.577 & 26.743 & 34.137 & 40.697 & 43.646 & 46.596 \\
\hline 22 & 10.496 & 23.827 & 25.926 & 33.094 & 39.454 & 42.314 & 45.173 \\
\hline 23 & 10.190 & 23.131 & 25.169 & 32.128 & 38.302 & 41.078 & 43.854 \\
\hline 24 & 9.905 & 22.484 & 24.465 & 31.229 & 37.231 & 39.929 & 42.627 \\
\hline
\end{tabular}

Sumber: Perhitungan

Debit banjir rencana ini akan dihitung dengan menggunakan kala ulang 2 tahun, 5 tahun, 10 tahun, 25 tahun, 50 tahun, 75 tahun dan 100 tahun dengan menggunakan tiga metode yaitu: metode rasional, metode weduwen dan metode haspers. Debit banjir ini nantinya akan digunakan dalam perencanaan atau analisa hidraulika untuk mendapatkan hasil yang akhir berupa dimensi saluran yang sesuai dengan debit banjir rencana yang telah diperhitungkan.

Tabel 2. Perhitungan debit banjir rencana metode rasional

\begin{tabular}{|c|c|c|c|c|c|c|c|}
\hline $\begin{array}{c}\mathrm{KU} \\
(\mathrm{Thn})\end{array}$ & Konstanta & $\mathrm{C}$ & $\begin{array}{c}\mathrm{T}_{\mathrm{c}} \\
(\mathrm{Jam})\end{array}$ & $\begin{array}{c}\mathrm{R}_{24} \\
(\mathrm{~mm})\end{array}$ & $\begin{array}{c}\mathrm{I} \\
(\mathrm{mm} / \\
\mathrm{jam})\end{array}$ & $\begin{array}{c}\mathrm{A} \\
\left(\mathrm{Km}^{2}\right)\end{array}$ & $\begin{array}{c}\mathrm{Qp} \\
\mathrm{m}^{3} / \mathrm{det}\end{array}$ \\
\hline 2 & 0.002778 & 0.825 & 1.0 & 237.71 & 81.215 & 125.00 & 23.2666 \\
\hline 5 & 0.002778 & 0.825 & 1.0 & 539.61 & 184.361 & 125.00 & 52.816 \\
\hline 10 & 0.002778 & 0.825 & 1.0 & 587.166 & 200.609 & 125.00 & 57.4707 \\
\hline 25 & 0.002778 & 0.825 & 1.0 & 749.5 & 256.071 & 125.00 & 73.3596 \\
\hline 50 & 0.002778 & 0.825 & 1.0 & 893.533 & 305.281 & 125.00 & 87.4573 \\
\hline 75 & 0.002778 & 0.825 & 1.0 & 958.292 & 327.406 & 125.00 & 93.7958 \\
\hline 100 & 0.002778 & 0.825 & 1.0 & 1023.05 & 349.532 & 125.00 & 100.134 \\
\hline
\end{tabular}

Sumber: Perhitungan

Dari hasil perhitungan yang telah dilakukan dengan menggunakan tiga metode di atas untuk mencari debit banjir, maka ditetapkan bahwa nilai yang diambil adalah nilai debit banjir yang dicari dengan menggunakan metode rasional dengan kala ulang selama dua tahun yaitu sebesar $23.267 \mathrm{~m}^{3} /$ det. Adapun pemilihan ini karena metode rasional lebih dianjurkan untuk digunakan dalam perhitungan debit banjir untuk pengerjaan drainase dan kala ulang 2 tahun diambil karena pengerjaan drainase digunakan dalam waktu yang dekat, maka nilai ulang 2 tahun dianggap cukup. 


\section{Analisa Hidraulika}

Menggunakan metode Trial And Error dan rumus: $\mathrm{Q}=\mathrm{V} \times \mathrm{A}$.

Dimana:

$Q=$ Debit banjir rencana

$\mathrm{V}=$ Kecepatan aliran (mengikuti ketentuan saluran trapesium; $1.5 \mathrm{~m} / \mathrm{det}$ )

$\mathrm{A}=$ Luasan dimensi

Sebelumnya, debit banjir yang digunakan adalah metode rasional dengan kala ulang 2 tahun, yang mana dibagi menjadi tiga kawasan yaitu: Hulu, Tengah dan Hilir sehingga didapatkan debit: 7.75553 $\mathrm{m}^{3} /$ det. Melalui metode Trial And Error didapatkan hasil A, sebagai berikut:

Tabel 3. Perhitungan A saluran drainase hilir

\begin{tabular}{|c|l|l|l|}
\hline \multicolumn{1}{|c|}{$\mathrm{A}$} & $\mathrm{B}$ & $\mathrm{m}$ & $\mathrm{h}$ \\
\hline 0.213 & 0.300 & 0.250 & 0.500 \\
\hline 0.263 & 0.400 & 0.250 & 0.500 \\
\hline 0.313 & 0.500 & 0.250 & 0.500 \\
\hline 0.591 & 0.600 & 0.250 & 0.750 \\
\hline 0.666 & 0.700 & 0.250 & 0.750 \\
\hline 0.703 & 0.750 & 0.250 & 0.750 \\
\hline 1.250 & 1.000 & 0.250 & 1.000 \\
\hline 1.700 & 1.200 & 0.500 & 1.000 \\
\hline 3.225 & 1.400 & 0.500 & 1.500 \\
\hline 3.375 & 1.500 & 0.500 & 1.500 \\
\hline 3.525 & 1.600 & 0.500 & 1.500 \\
\hline 4.331 & 1.600 & 0.500 & 1.750 \\
\hline 4.500 & 1.600 & 0.500 & 1.800 \\
\hline 5.200 & 1.600 & 0.500 & 2.000 \\
\hline
\end{tabular}

\section{Sumber: Perhitungan}

Antara ketiga kawasan didapatkan luasan dimensi saluran yang sama, karena besaran debit yang sama. Untuk lubang biopori resapan direncanakan:

$\mathrm{D} \quad=10 \mathrm{~cm} \quad=0.1 \mathrm{~m}$

$\mathrm{H} \quad=200 \mathrm{~cm} \quad=2.0 \mathrm{~m}$

Debit $=40 \mathrm{l} / \mathrm{det}=0.004 \mathrm{~m}^{3} / \mathrm{det}$

Akan dibuat disepanjang saluran drainase pada kedua sisi dengan jarak $10 \mathrm{~cm}$ antara satu lubang dengan lubang yang lainnya, sehingga didapatkan dalam satu meter panjang jumlah lubang biopori resapan adalah sebanyak 10 buah lubang, dengan debit total yang mampu ditampung sebagai berikut:

$$
\begin{aligned}
\text { Qtb } & =40 \times 10 \\
& =400 \mathrm{l} / \mathrm{det} \\
& =0.4 \mathrm{~m}^{3} / \mathrm{det}
\end{aligned}
$$

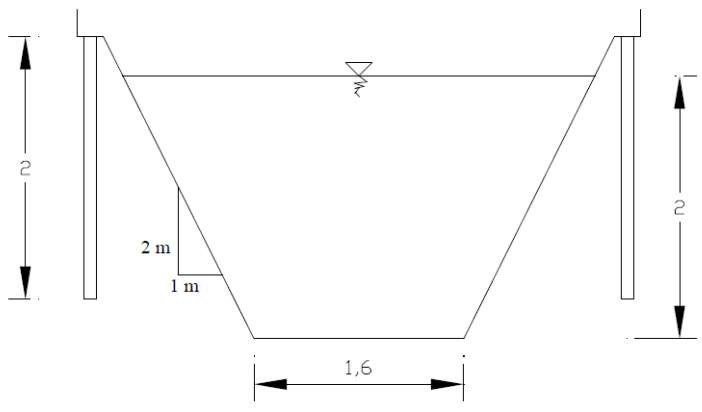


Gambar 2. Saluran drainase biopori resapan (potongan melintang)

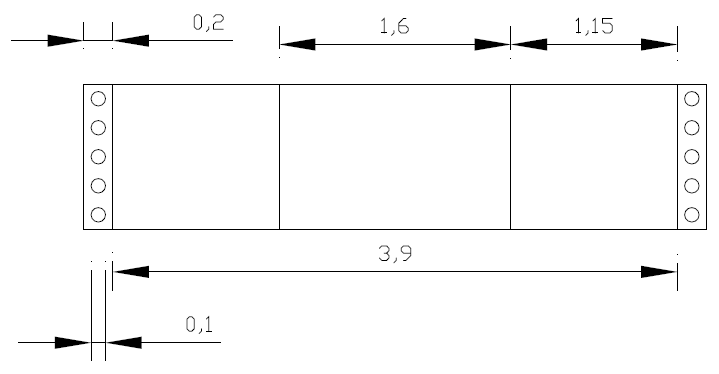

Gambar 3. Saluran drainase biopori resapan (potongan memanjang)

\section{SIMPULAN}

Adapun kesimpulan yang didapat sebagai berikut:

1. Debit banjir yang ditetapkan sebesar $23.267 \mathrm{~m}^{3} /$ det.

2. Dimensi saluran dengan bentuk trapesium, dengan $B=1.60 \mathrm{~m}, \mathrm{~h}=2 \mathrm{~m}$, dan $\mathrm{m}=0.5 \mathrm{~m}$.

3. Lubang biopori resapan dirancang dengan dimensi berbentuk lingkaran, D $=10 \mathrm{~cm}(0.1 \mathrm{~m})$ dan $\mathrm{H}=200 \mathrm{~cm}(2 \mathrm{~m})$ dan mampu menampung debit 40 l/det.

\section{DAFTAR PUSTAKA}

Hilwatullisan. (2009). Lubang Resapan Biopori (LRB) Pengertian dan Cara Membuatnya di Lingkungan Kita. Politeknik Negeri Sriwijaya. Palembang. Hasmar, Halim. (2012). Drainase Terapan UII Press. Yogyakarta.

Harto, Sri. (2009). Hidrologi: Teori, Masalah, Penyelesaian . Nafiri Offset. Yogyakarta.
Made Kamiana, I. (2011). Teknik Perhitungan Debit Rencana Bangunan Air. Graha Ilmu. Jakarta. SN. (TT). Drainase Perkotaan. Gunadarma. Jakarta. Soewarno. (1995). Hidrologi:Aplikasi Metode Statistik Untuk Analisa Data Jilid 1. Nova. Bandung. Soewarno. (1995). Hidrologi:Aplikasi Metode Statistik Untuk Analisa Data Jilid 2. Nova. Bandung. Suripin. (2003). Sistem Drainase Perkotaan Yang Berkelanjutan. Andi. Yogyakarta.

Te Chow, Van. (1994). Hidraulika Saluran Terbuka. Erlangga. Jakarta.

Triatmodjo, Bambang. (2011). Hidraulika II. Beta. Yogyakarta. 